were abundant, complete inhibition was achieved. Rat gastric fundus was, for example, completely effective as an absorbing agent in inhibiting staining of human gastric parietal cells by the pernicious anaemia serum.

The relatively poor and somewhat inconstant staining of rodent gastrointestinal mucosa by the rabbit antiserum is worthy of comment. As the serum had been prepared in a rabbit, its lesser reaction with this and other rodents can perhaps be attributed to a partial failure to develop gastrointestinal autoimmunity or immunity against too closely related gastrointestinal antigens of the other rodents. In earlier investigations of the properties of the antiserum ${ }^{2}$, staining of rodent gastrointestinal mucosa was not observed in the few animals examined. The present positive results are presumably the outcome of working with different animal strains in larger numbers and perhaps of the introduction of liquid nitrogen snapfreezing as a technical improvement in preserving tissue antigens for immunohistology. The last-mentioned point may also explain the present failure to confirm our previous tentative suggestion that there might be systematic differences in the anatomical distribution of gastrointestinal staining by the rabbit serum between ruminants and carnivores. The negative findings in some young animals (pup and kitten) reflect some species variation when compared with the positive results in human foetuses and in the lamb.

Perhaps the most interesting observation from the present investigation is the demonstration of closer antigenic similarity between placental and monotreme colonic mucosa than the marsupial, in contrast with the total absence of gastric parietal cell antigen in the monotremes, though abundant in placentals and marsupials. The limitation of the gastrointestinal antigens to the mammals also differs from the distributional behaviour of a kidney-specific material demonstrated in various vertebrates including mammals, birds and fish ${ }^{1}$.

We thank the Department of Fisheries and Wildlife for help in gathering the specimens, and Miss R. M. Stevens, Mr. A. Maxwell and Mr. D. Quinn for technical assistance. The work was supported by grants from the Anti-Cancer Council of Victoria and the National Health and Medical Research Council.

R. C. NATRN

W. G. R. M. DE BOER

Department of Pathology,

Monash University,

Melbourne.

${ }^{1}$ Nairn, R. C., Ghose, T., Fothergill, J. E., and McEntegart, M. G., Nature, 196, 385 (1962).

Nairn, R. C., Fothergill, J. E., McEntegart, M. G., and Porteous, I. B., Brit. Med. J., 1788 (1962).

${ }^{3}$ de Boer, W. G. R. M., Nairn, R. C., and Maxwell, A., J. Clin. Path., 18, 456 (1965).

s Nairn, R. C., Fluorescent Protein Tracing, second ed. (Livingstone, Edinburgh, 1964).

\section{Growth of L1210 Leukaemia Cells}

There is evidence that the number or size of the cell inoculum, the site of inoculation, the host of origin or the conditioning of the host ${ }^{1}$ can alter the strain specificity of neoplasms and that some neoplasms can be transplanted from strain of origin and grow progressively in homologous strains with the animals dying of the neoplastic disease. Greene $^{2}$ reported the successful transplantation of heterologous neoplasms into the brains of rats and mice and suggested that the brain might be exempt from any immunological response.

The present communication concerns investigations of the progressive growth of leukaemia $L 1210$ implanted intracerebrally at various log-dose inocula into homologous strains of mice which grew $(B D F 1, C D B A)$ or regressed $(C 3 H, C 57 B L / 6)$ when an intraperitoneal inoculation of $5 \times 10^{6}$ cells was used.

Leukaemia $L 1210$ cells wore collected from a $D B A / 2$ host which had been inoculated intraperitoneally 6 days previously. A cell count was carried out and the stock was diluted with cold Earlo's balanced salt solution (EBSS) so that the cell inoculum was injected intracerebrally ini $0.025 \mathrm{ml}$. using a microlitre syringe (Hamilton Co.) by penetrating the skull with a 27 -gauge needle. Ten mice of each strain ( $B D F 1, C D B A, C 3 H$ and $C 57 B L / 6)$ were used at each dose-level. The animals were observed daily for survival and subsequent death due to tumour growth.

The results (Table 1) indicate that the intracerebrally implanted $L 1210$ was lethal to compatible hosts $\left(B D F_{1}\right.$ and $C D B A$ ) with an inoculation of ten cells, whereas the number of cells necessary to kill more than 50 per cent of the mice was greater than ten cells for $\mathrm{C} 3 \mathrm{H}$ mice and greater than 1,000 cells for $C 57 B L / 6$ mice.

The data reveal that, at the higher cell inocula, $L 1210$ grows progressively in the brain probably because of its ability to overcome an immunological response, whereas at lower cell inocula the immune mechanism exists but is not as effective as the response elicited by the intraperitoneal inoculation of the leukaemia cells.

It would appear that each mouse strain may have its own threshold level for growth of incompatible neoplasms when brain is used as the site of inoculation. This may, in turn, be an expression of the antigenicity of each tumour or the natural resistance of the host.

This investigation was supported by a contract with the Cancer Chemotherapy National Service Center, National Cancer Institute, National Institutes of Health.

\section{ISIDORE WODINSKY}

\section{J. Kenster}

Arthur D. Little, Inc., Life Sciences Division, Cambridge, Massachusetts.

${ }^{1}$ Snell, G. D., Physiopathology of Cancer, edit. by Homburger, F., 293 (Hoeber-Harper, New York, 1959).

${ }^{2}$ Greene, H. S. N., Cancer Res., 11, 529 (1951).

\section{PATHOLOGY}

\section{Carcinogenic Action of N-Methyl-N'-nitro- $N$-nitrosoguanidine}

$N$-Methyl- $N^{\prime}$-nitro- $N$-nitrosoguanidine (NG) is known to be a potent mutagenic substance for Escherichia coli. Salmonella typhimurium ${ }^{2}$, and Chlamydomonas reinhardi ${ }^{3}$. Induction of chromosomal aberrations in the cells of root meristems of Vicia faba by $\mathrm{NG}$ has been reported ${ }^{4}$. It is claimed that $N G$ is the most potent mutagen yet discovered, since NG induced at least one mutation per cell of Escherichia coli treated at the optimal condition permitting 50 per cent survival ${ }^{5}$. The production of a number of multi-site mutants resulting from the accumulation of single-site mutations has boen noticed $\mathrm{d}^{2,5}$.

This report deals with the carcinogenic activity of $\mathrm{NG}$. $\mathrm{NG}$ was purchased from $\mathrm{K}$ and $\mathrm{K}$ Laboratories, Ine.. New York, and was dissolved in warmed sterile saline at a concentration of $5 \mathrm{mg}$ per $\mathrm{ml}$. Wistar strain male rats,

Table 1. Mean Survival Trmes of Mice inoculated with LeUkaemia L1210 intracerfbrally

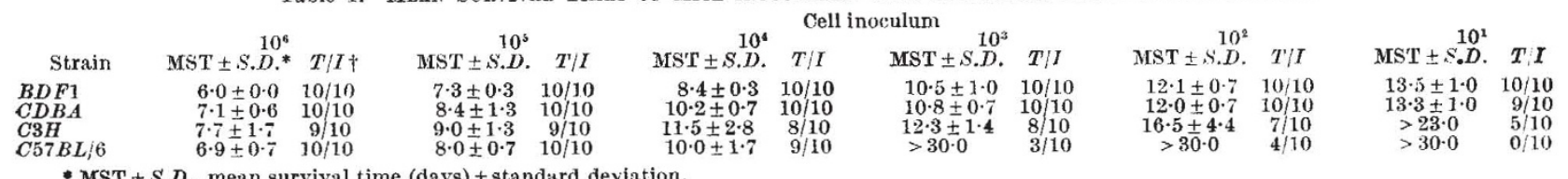

- MST \pm S.D., mean survival time (days) \pm standard deviation.

$+T / I$, No. of tumour deaths/No. of mice inoculated. 